\title{
Prevalence of Zoonotic Pathogens in Domestic and Feral Cats in Shanghai, with Special Reference to Salmonella
}

\author{
Halim $\mathrm{A}^{1^{*}}$, Bhekharee $\mathrm{AK}^{1}$, Feng $\mathrm{M}^{2}$, Cheng $\mathrm{X}^{2^{*}}$, Halim $\mathrm{M}^{3^{*}}$ \\ ${ }^{1}$ Zhongshan Hospital, Shanghai Medical College of Fudan University, Shanghai, China \\ ${ }^{2}$ Department of Medical Microbiology and Parasitology, School of Basic Medical Sciences, Fudan University, Shanghai 200032, \\ China \\ ${ }^{3}$ University of Salford, MSc Biomedical Science, Greater Manchester, United Kingdom
}

Corresponding Author(s): Alice Halim*, Xunjia Cheng* and Michael Halim**

Address: *Zhongshan Hospital, Shanghai Medical College of Fudan University, Shanghai, China. **University of Salford, MSc Biomedical Science, Greater Manchester, United Kingdom.

Received date: 10 December 2020; Accepted date: 07 January 2021; Published date: 15 January 2021

Citation: Halim A, Bhekharee AK, Feng M, Cheng X, Halim M. Prevalence of Zoonotic Pathogens in Domestic and Feral Cats in Shanghai, with Special Reference to Salmonella. J Health Care and Research. 2021 Jan 15;2(1):1-12.

Copyright (C) 2021 Halim A, Bhekharee AK, Feng M, Cheng X, Halim M. This is an open-access article distributed under the Creative Commons Attribution License, which permits unrestricted use, distribution, and reproduction in any medium, provided the original work is properly cited.

\begin{abstract}
Interacting with domestic or feral cats comes with both pleasure and harm. This research has attempted to study the role of cats in Shanghai, China, being vectors of disease and the risk they pose to public health. Polymerase Chain Reaction (PCR), gel electrophoresis, molecular cloning, and DNA sequencing were methods used to compare the prevalence of zoonotic bacteria and parasites in domestic and feral cats. Phylogenetic trees were created for further analysis. From this study involving 30 cats and 12 zoonotic pathogens, four pathogens were identified in our stool samples using PCR: Escherichia coli, Campylobacter spp., Salmonella spp., and Toxocara cati. In total, $60 \%$ of the kittens had enteric zoonoses in their stools while $30 \%$ of the adult cats' stools contained enteric zoonoses. Salmonella enterica subspecies enterica, which is the leading cause of Salmonellosis in developed countries, was present in two samples inferred from sequencing and phylogenetic tree analysis.
\end{abstract}

\section{Keywords}

Zoonotic Pathogen, Zoonosis, Cat Stool, Pet, Salmonella, Public Health, Infectious Disease, PCR, Primer, Phylogenetic Tree

\section{Introduction}

Zoonotic diseases are transmitted by bacteria, parasites, and viruses between vertebrate animals and humans; at least $61 \%$ of all human pathogens are zoonoses [1]. The prevalence of zoonotic diseases in urban settings is far more common than we could imagine. Feral cats, dogs, and house pets are potential reservoirs for a number of zoonoses. Close interactions with these animals significantly increase the risk of humans unknowingly being infected with zoonotic pathogens [2]. Over the past years, the Chinese population rearing cats and dogs as pets has increased due to improvements in overall lifestyle. By 2017, there were at least 53 million pet cats (https://www.mapsofworld.com/world-topten/countries-with-most-pet-cat-population.html) and 27 million pet dogs in China. (https://www.mapsofworld.com/world-topten/countries-with-most-pet-dog-population.html) 
In Shanghai, an urban city in China, we often observed students closely interacting with feral cats in university campuses. There were also reports of students rearing feral cats in their dormitory rooms. A lack of awareness that animals could be potential reservoirs of zoonotic diseases is a great risk that increases one's exposure to infection, which poses a zoonotic hazard to both human health and the community [3]. Prominent feline zoonoses include: Toxoplasma gondii, Bartonella henselae, Toxocara cati, Rickettsia felis, enteropathogenic Escherichia coli and the emerging feline-related Corynebacterium ulcerans [4]. Cryptosporidium parvum and Toxoplasma gondii are high-risk zoonotic pathogens, while Echinococcus spp. are low-risk pathogens [5]. In a study involving 9 cats, $67.5 \%$ were found to have Giardia spp. (57.1\%), Cryptosporidium spp. (1.4\%), Ancylostoma tubaeforme (1.1\%), and T. cati (1.1\%) [6].

According to a study conducted in Central China, 360 cat stools were microscopically examined for intestinal parasites: $64(17.78 \%)$ were infected with $T$. cati, 61 (16.94\%) with Isospora felis, 41 (11.39\%) with Isospora rivolta, 33 (9.17\%) with Paragonimus, 23 (6.39\%) with hookworms, 11 (3.06\%) with Toxoplasma-like oocysts, 10 (2.78\%) with Trichuris, 4 (1.11\%) with lungworm, 2 (0.56\%) with Sarcocystis, and $1(0.28 \%)$ with trematode [7]. Statistical analysis suggested that cats living outdoors are an essential factor contributing to the presence of zoonotic pathogens found in cat stools [7]. Another study in Guangzhou, China, investigated the prevalence of $T$. gondii, where $30.77 \%$ of feral cats and $17.98 \%$ of domestic cats were positive for $T$. gondii; similarly in Lanzhou, a $T$. gondii prevalence of $21.3 \%$ in pet cats was reported, indicating a high prevalence of $T$. gondii in cats from China [3].

We hypothesize that dietary factors may also play an important role in the prevalence of enteric zoonoses in cats. For instance, feral cats hunt rodents and birds, which harbor a number of pathogens, making them more likely to acquire and transmit diseases to humans $[8,9]$. Additionally, if domestic cats are fed with raw meat, the likelihood of contracting Salmonella spp. increases significantly [10]. It is worth mentioning that some zoonotic pathogens are more likely to be present in kittens than in adult cats, such as $T$. cati and Giardia spp. Parasites [11,12].

The present study aims to determine the prevalence of 12 different zoonotic pathogens in cats and compare them according to two risk factors: age (adult or kitten) and living conditions (feral or domestic) in Shanghai, China, with an emphasis on the bacterial zoonosis: Salmonella.

\section{Materials and Methods}

\section{Stool samples:}

This cross-sectional study was carried out throughout June-September 2017 in Shanghai, China. 30 cat stool samples were randomly collected across Shanghai, which was accomplished by: collaborating with volunteers from various shelters in different districts, involving volunteers from different universities to send stool samples of their campus' feral cats, implementing trapping and releasing of feral cats in our university campus, and involving domestic cat owners and their friends and families to send us their cats' stools. In total, 15 stool samples were obtained from domestic cats while the other half were obtained from stray cats. Out of the 15 stool samples, 10 belonged to adult cats while 5 belonged to kittens.

\section{Stool Examination and Culture:}

All stool samples collected were stored at $-20^{\circ} \mathrm{C}$ within 24 hours of collection.

\section{PCR Analysis:}

Genomic DNA was extracted from 30 stool samples using the QIAamp DNA Stool Mini Kit and stored at $20^{\circ} \mathrm{C}$ when unused; they were thawed prior to performing PCR. The genomic DNA was subjected to PCR for the amplification of 12 different DNA genes based on their respective primers as shown in Table-1. A total of 15 primer pairs were used, of which 4 pairs of primers for Toxoplasma gondii, Toxocara cati, Trematoda spp. and Entamoeba histolytica were designed in this study using BioEdit and BLAST (www.ncbi.nlm.nih.gov/BLAST/).

Briefly, standardized PCR protocol was carried out throughout our study in a 2oul reaction mixture using 
Citation: Halim A, Bhekharee AK, Feng M, Cheng X, Halim M. Prevalence of Zoonotic Pathogens in Domestic and Feral Cats in Shanghai, with Special Reference to Salmonella. J Health Care and Research. 2021 Jan 15;2(1):1-12.

\section{Original Article}

TaKaRa's PCR Amplification Kit. A total of 30 to 35 cycles of PCR were performed as follows: initial 3-min denaturation at $94^{\circ} \mathrm{C}$, followed by denaturation at $94^{\circ} \mathrm{C}$ for $15 \mathrm{~s}$, annealing at $50^{\circ} \mathrm{C}$ to $60^{\circ} \mathrm{C}$ for 30 , polymerization at $72^{\circ} \mathrm{C}$ for 30 , and a final $7^{-}$ min polymerization step at $72^{\circ} \mathrm{C}$. Initially, $30 \mathrm{PCR}$ cycles were used during the experiment; 35 cycles were implemented for repeats. Optimal annealing temperatures $\left(50^{\circ} \mathrm{C}, 55^{\circ} \mathrm{C}\right.$ and $\left.60^{\circ} \mathrm{C}\right)$ were selected according to the primers' GC content.

Table-1: The primers used in this study to amplify target genes in DNA samples by PCR

\begin{tabular}{|c|c|c|c|c|}
\hline Pathogen & Primer & Primer Sequence $\left(5^{\prime} \rightarrow\right.$ 3') & $\begin{array}{c}\text { PCR size / } \\
\text { bp }\end{array}$ & Reference \\
\hline \multicolumn{5}{|l|}{ Bacteria } \\
\hline \multirow{2}{*}{$\begin{array}{l}\text { Escherichia coli (EHEC } \\
\text { / EPEC) }\end{array}$} & Eae-R & GTAAAGTCCGTTACCCCAACCTG & \multirow{2}{*}{482} & \multirow{2}{*}{ [13] } \\
\hline & Eae-F & TCAATGCAGTTCCGTTATCAGTT & & \\
\hline \multirow{2}{*}{ Shigella spp. } & ipaH-R & CCAGTCCGTAAATTCATTCT & \multirow{2}{*}{423} & \multirow{2}{*}[14]{} \\
\hline & ipaH-F & TGGAAAAACTCAGTGCCTCT & & \\
\hline \multirow{2}{*}{ Salmonella spp. } & ipaB-R & GCCTCTCCCAGAGCCGTCTGG & \multirow{2}{*}{314} & \multirow{2}{*}[15]{} \\
\hline & ipaB-F & GGACTTTTTAAAAGCGGCGG & & \\
\hline \multirow{2}{*}{ Campylobacter spp. } & CadF-R & TCAAGTCTTAAAGCCAAAGAATC & \multirow{2}{*}{119} & \multirow{2}{*}[16]{} \\
\hline & CadF-F & AGCAGGTGGAGGATATGAGG & & \\
\hline \multicolumn{5}{|l|}{ Parasites } \\
\hline \multirow{4}{*}{ Toxoplasma gondii } & Tg-SAG-R & GCTTCCTTCTTGATCGTTAG & \multirow{2}{*}{276} & \multirow{2}{*}[17]{} \\
\hline & Tg-SAG-F & ATCGGTCGTCAATAATGTCG & & \\
\hline & Tg-366-R & AAAGGGGTTTGGATTCCTATCATTCCA & \multirow{2}{*}{366} & \multirow{2}{*}{ This study } \\
\hline & Tg-366-F & ATGCGCACATGCCTCTTCCCCTG & & \\
\hline \multirow{4}{*}{ Toxocara cati } & Tc-ITS-R & TAGTTTCTTTTCCTCCGCT & \multirow{2}{*}{375} & \multirow{2}{*}[18]{} \\
\hline & Tc-ITS-F & GGAGAAGTAAACTC & & \\
\hline & Tc-209-R & AAGTCAGAGGTTCGAAGGCG & \multirow{2}{*}{209} & \multirow{2}{*}{ This study } \\
\hline & Tc-209-F & CAAATTAAGCCGCAGGCTCC & & \\
\hline \multirow{2}{*}{ Trematoda spp. } & Trematode-R & ACTAAAGAAAACAGCAGT & \multirow{2}{*}{$200-300$} & \multirow{2}{*}{ This study } \\
\hline & Trematode-F & TTTCAGCATTTGTTTTGG & & \\
\hline \multirow{4}{*}{ Entamoeba histolytica } & ITS2-R & TCATTCGCCATTACTTAAGAAATCATTGTT & \multirow{2}{*}{$400-500$} & \multirow{2}{*}{ [19] } \\
\hline & ITS1-F & AGGTGAACCTGCGGAAGGATC ATTA & & \\
\hline & Entam2-R & CAGATCTAGAAACAATGCTTCTCT & & \\
\hline & Entam1-F & GTTTTATACATTTTGAAGACTTTATG & $400-500$ & This study \\
\hline & Ecoli-R & GATTTCTACAATTCTCTTGGCATA & & \\
\hline Entamoeba coli & Ecoli-F & GAATGTCAA AGCTAATACTTGACG & 100 & {$[20]$} \\
\hline Dloctountic homini & Blast-1017 & TGCTTTCGCACTTGTTCATC & -50 & [01] \\
\hline 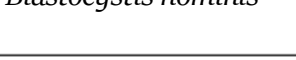 & Blast-505 & GGAGGTAGTGACAATAAATC & 300 & \\
\hline Cryptosporidium & Crypto-nest-1R & GCAGCTGCTAATCTTCTTAGTGC & -00. & Г2ר \\
\hline parvum & Crypto-nest-1F & AAAGAAGCACCTCCTGTTTCAG & 500 & {$[22]$} \\
\hline & Giar-nest-1R & CTGCTGCCGTCCTTGGATGT & & \\
\hline Glardıa spp. & Giar-nest-1F & AAGTGTGGTGCAGACGGACTC & 500 & {$[2$} \\
\hline
\end{tabular}




\section{Gel Electrophoresis and DNA Sequencing:}

The PCR products were subjected to gel electrophoresis using $2 \%$ ethidium-stained agarose gel. Genomic DNA were mixed with TaKaRa 6x purple DNA loading dye and pipetted into the wells, which were ran for 20 minutes at $100 \mathrm{~V}$. The agarose gel was visualized under $312 \mathrm{~nm}$ wavelength of ultraviolet light using SmartView.

Positive PCR products were extracted using AxyPrep DNA Gel Extraction Kit and purified with QIAquick PCR Purification Kit prior to sequencing. Weakly positive bands and PCR products that failed to sequence by Thermo Fisher Scientific Company were proceeded with ligation according to TaKaRa's DNA Ligation Kit Protocol, followed by transformation into viable Escherichia coli cells, selective bacterial culture, inoculation, harvesting of plasmid DNA post-digestion using HindIII, and finally, performing gel electrophoresis to verify successful DNA ligation before sending for sequencing.

\section{DNA Sequence Analysis:}

DNA sequences received from Thermo Fisher
Scientific Company were analyzed by comparing them with nucleotide sequences from the GenBank database (https://www.ncbi.nlm.nih.gov/) and using BLAST (www.ncbi.nlm.nih.gov/BLAST/) in order to determine the genomic DNA's identity.

\section{Phylogenetic Analysis:}

Analysis of multiple DNA sequences was performed using Molecular Evolutionary Genetics Analysis (MEGA), where phylogenetic trees were constructed using the neighbor-joining method.

\section{Results}

\section{PCR Analysis:}

From our positive samples seen in Fig-1, three out of four zoonotic pathogens are bacterial species. However, the most prevalent zoonotic pathogen is the parasite T. cati (42.9\%), followed by EPEC / EHEC (35.7\%), Salmonella spp. (14.3\%) and eventually Campylobacter spp. (7.1\%). In total, more pathogens were present in feral cats $(71.4 \%)$ than domestic cats (28.4\%). Additionally, an equal number of pathogens are found in both feral kittens and domestic kittens (21.4\%).

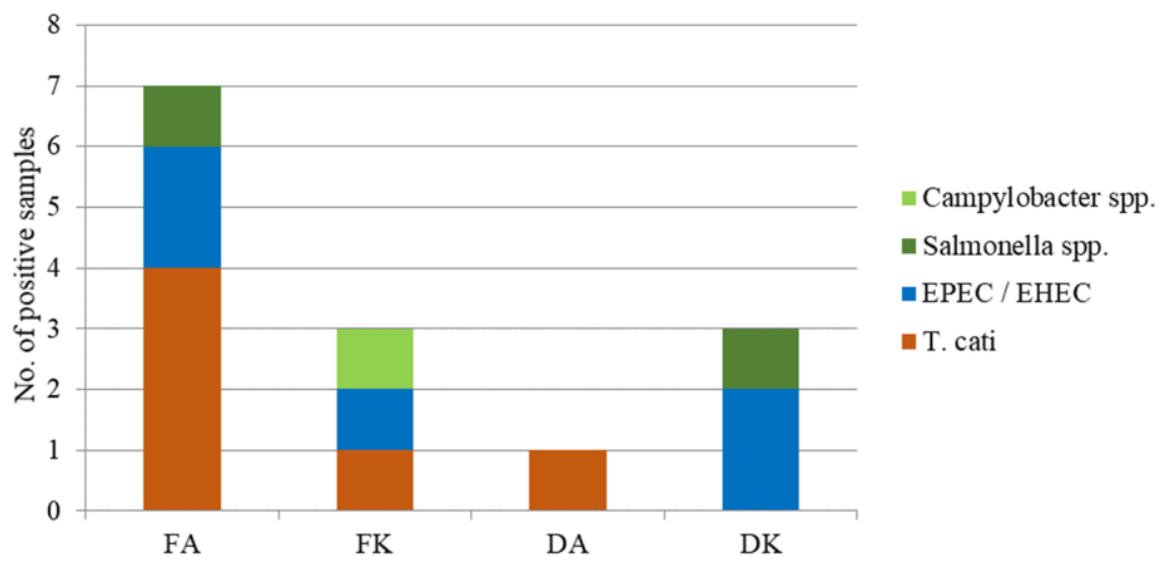

Fig-1: Proportion of pathogens detected in stools of feral adult cats, feral kittens, domestic adult cats and domestic kittens using PCR analysis.

$D=$ Domestic; $K=$ Kitten; $F=$ Feral; $A$ = Adult cat

\section{DNA Sequence Analysis:}

Positive stool samples detected using PCR and gel electrophoresis were selected and sent to Thermo Fisher Scientific Company for sequencing. Subsequently, the DNA sequences were analyzed by comparing sequences retrieved from GenBank database and via BLAST to identify sequence similarity.
Table-2 showed samples DK3, DK5, FA3, FA4 and FK1 positive for pathogenic $E$. coli with $99 \%$ similarity to the eae nucleotide sequence. Samples DK4 and FA6 were also positive for $S$. enterica with $99 \%$ and $96 \%$ similarities to the ipaB nucleotide sequence according to the GenBank database. 
Citation: Halim A, Bhekharee AK, Feng M, Cheng X, Halim M. Prevalence of Zoonotic Pathogens in Domestic and Feral Cats in Shanghai, with Special Reference to Salmonella. J Health Care and Research. 2021 Jan 15;2(1):1-12.

\section{Original Article}

Table-2: Selected PCR-positive samples sent for sequencing and analyzed using BLAST

\begin{tabular}{|c|c|c|c|c|c|}
\hline \multirow{2}{*}{ Sample } & \multirow{2}{*}{ Primer } & \multirow{2}{*}{$\begin{array}{c}\text { Amplicon size / } \\
\text { bp }\end{array}$} & \multirow{2}{*}{ Potential Pathogen } & \multicolumn{2}{|c|}{ BLAST result } \\
\hline & & & & Similarity & Pathogen identity \\
\hline $\mathrm{DK}_{3}$ & eae & 482 & E. coli (EPEC/EHEC) & $99 \%$ & E. coli (EPEC / EHEC) \\
\hline $\mathrm{DK}_{5}$ & eae & 482 & E. coli (EPEC/EHEC) & $99 \%$ & E. coli (EPEC / EHEC) \\
\hline FA3 & eae & 482 & E. coli (EPEC/EHEC) & $99 \%$ & E. coli (EPEC / EHEC) \\
\hline $\mathrm{FA}_{4}$ & eae & 482 & E. coli (EPEC/EHEC) & $99 \%$ & E. coli (EPEC / EHEC) \\
\hline FK1 & eae & 482 & E. coli (EPEC/EHEC) & $99 \%$ & E. coli (EPEC / EHEC) \\
\hline DA1 & Entam & 600 & Unknown & $95 \%$ & Euphorbiaceae \\
\hline DA2 & Entam & 600 & Unknown & $99 \%$ & Gregarina blattarum \\
\hline $\mathrm{DK}_{4}$ & ipaB & 314 & Salmonella spp. & $99 \%$ & Salmonella enterica \\
\hline FA6 & ipaB & 314 & Salmonella spp. & $96 \%$ & Salmonella enterica \\
\hline FA9 & Tc-ITS & 375 & T. cati & Unknown & Unknown \\
\hline FA10 & Tc-ITS & 375 & T. cati & Unknown & Unknown \\
\hline
\end{tabular}

Samples DA1 and DA2 were positive for our selfdesigned Entam primer at 6oobp for E. histolytica, however DNA analysis revealed $99 \%$ similarity to a Euphorbiaceae plant and a Gregarina parasite respectively. No organisms were identified for $T$. cati samples FA9 and FA10 despite showing strong evidence for ITS gene on gel electrophoresis Fig-2 and Fig-3.

\section{Phylogenetic Analysis:}

Construction of Phylogenetic trees using the neighbour-joining method (Fig-4 and Fig-5).

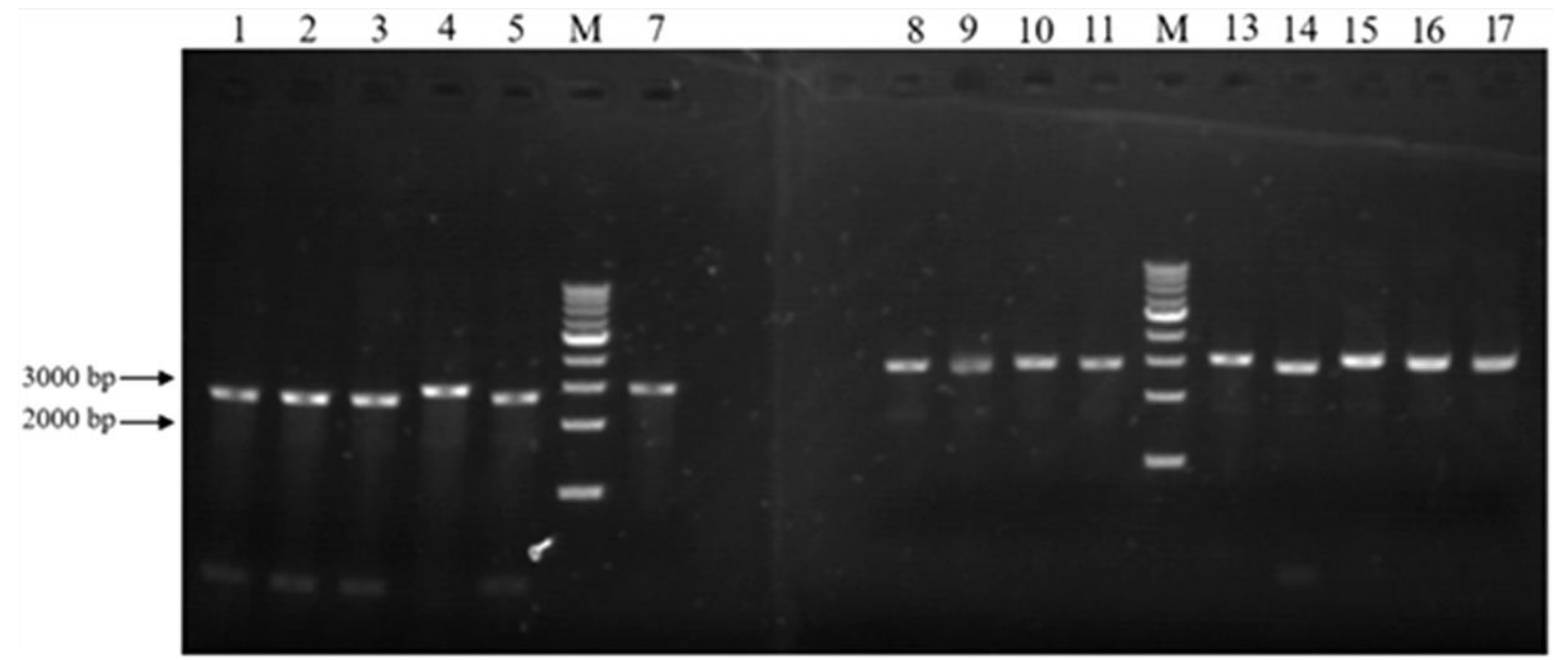

Fig-2: Gel electrophoresis of recombinant plasmids after restriction digest by HindIII enzyme.

The plasmid vector was 270obp. The two inserts used were ipaB gene at $314 \mathrm{bp}$ and ITS gene at 375 bp.

Lane M: Marker (1Kbp ladder); Lanes 1-5: DK4 (ipaB gene); 7-11: FA6 (ipaB gene); 13-17: FA9 (ITS gene).

$D=$ Domestic $K=$ Kitten $F=$ Feral; $A$ = Adult cat 
Citation: Halim A, Bhekharee AK, Feng M, Cheng X, Halim M. Prevalence of Zoonotic Pathogens in Domestic and Feral Cats in Shanghai, with Special Reference to Salmonella. J Health Care and Research. 2021 Jan 15;2(1):1-12.

\section{Original Article}

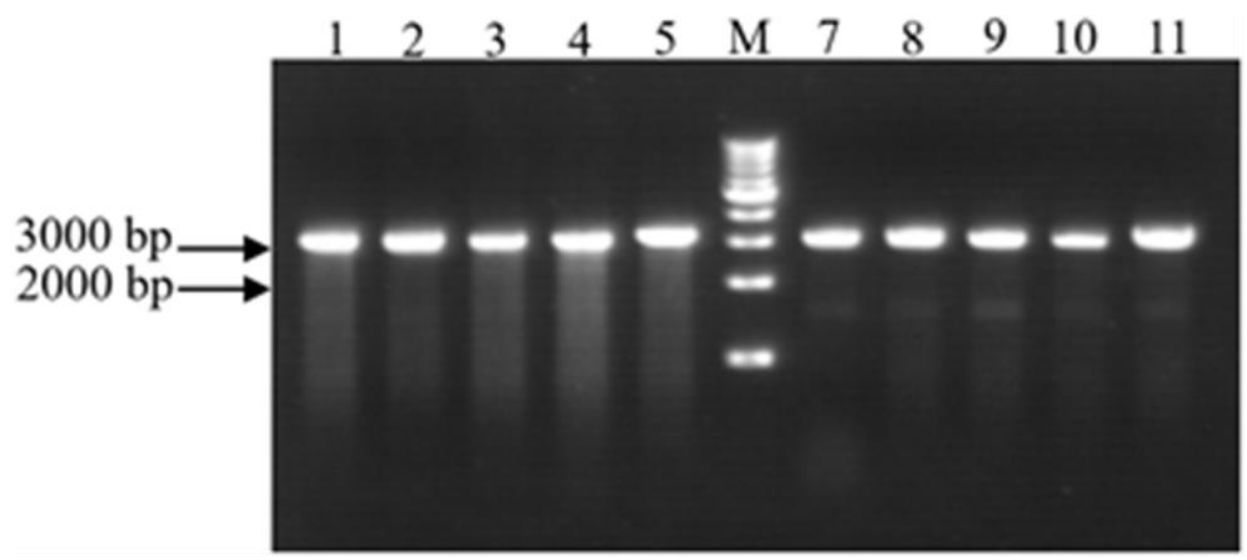

Fig-3: Gel electrophoresis of recombinant plasmids after restriction digest by HindIII enzyme.

The plasmid vector was 270obp. The insert used was an ITS gene at 375 bp.

Lane M: marker (1Kbp ladder); Lanes 1-5 and 7-11: FA10 (ITS gene)

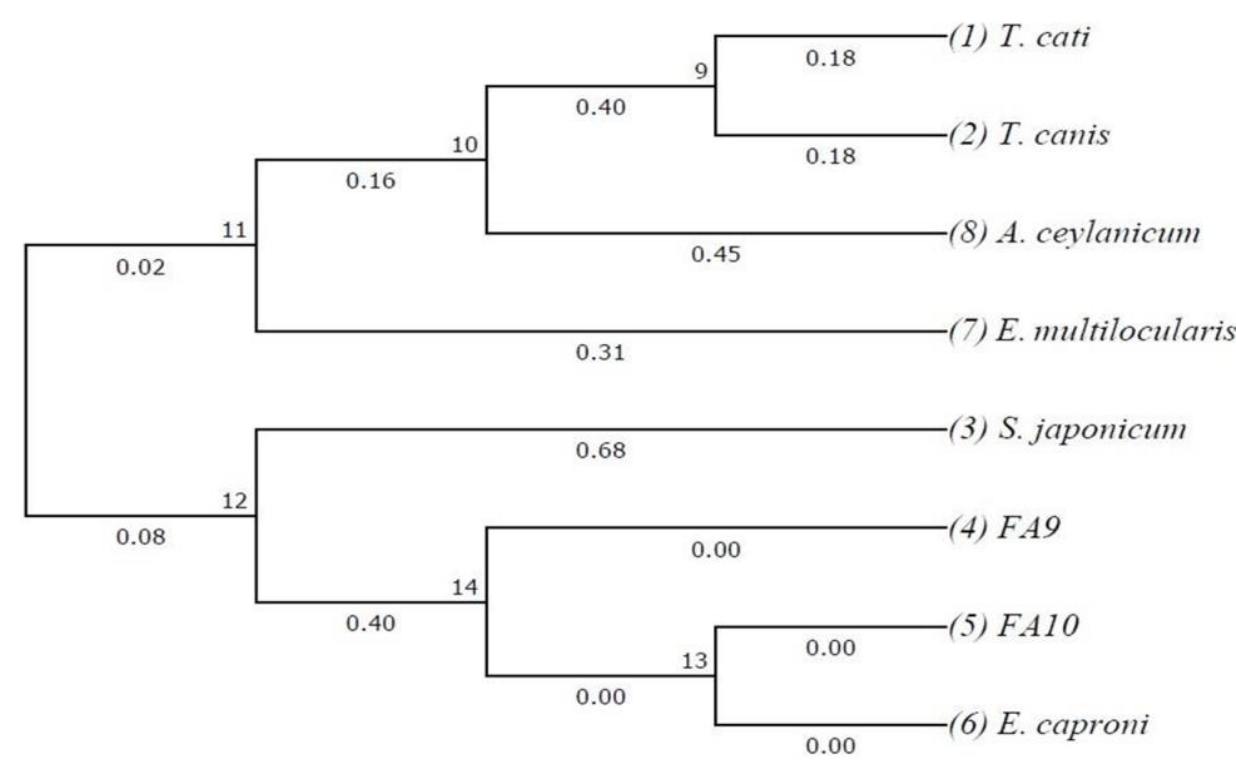

Fig-4: A Neighbor-Joining (NJ) phylogenetic tree demonstrating the evolutionary relationships among zoonotic helminths known to infect pets, including $T$. cati positive PCR samples FA9 and FA1o.

$D=$ Domestic $K=$ Kitten $F=$ Feral $; A=$ Adult cat

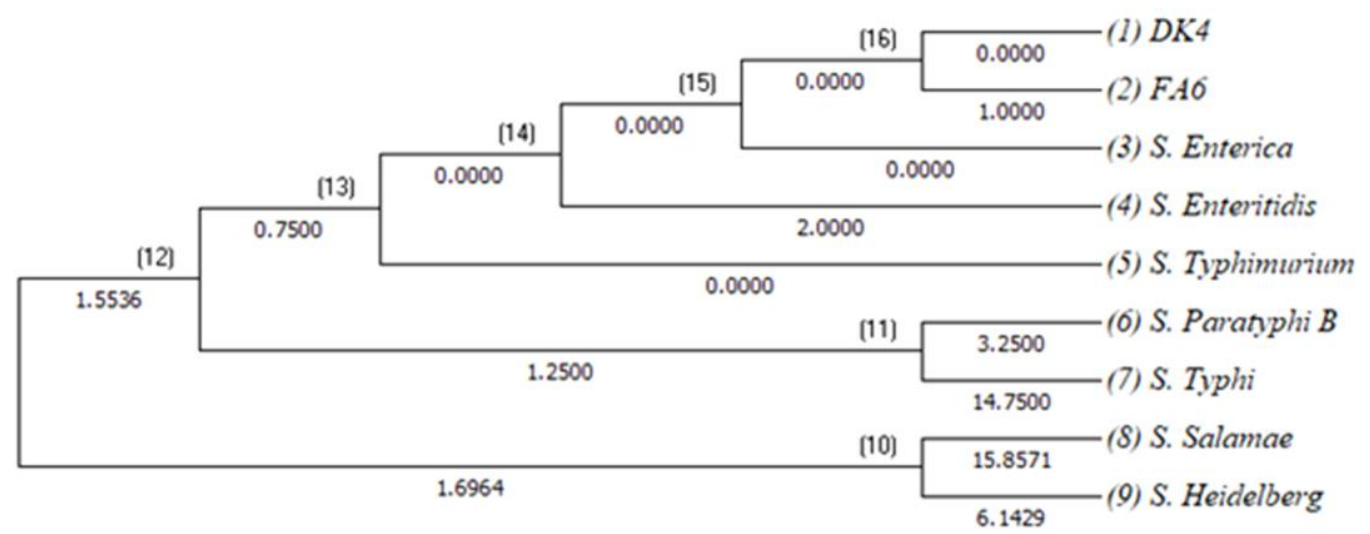

Fig-5: An NJ phylogenetic tree demonstrating the evolutionary relationships among Salmonella species and subspecies, including $S$. enterica positive samples DK4 and FA6.

$D=$ Domestic $;=$ Kitten $;=$ Feral $; A=$ Adult cat 


\section{Discussion}

At the beginning of our study, we hypothesized that zoonotic agents would be more prevalent in kittens than adult cats, and specifically more kittens would be infected with parasites due to a relatively weaker immune system. Our findings revealed that $60 \%$ of the kittens' stools contained enteric zoonoses while $30 \%$ of the adult cats' stools contained enteric zoonoses. This supports our hypothesis, given the immune systems of kittens are still less immunocompetent, as they have not been fully developed, thereby increasing their susceptibility to infections [24]. Similarly, immunocompromised populations such as pregnant women, young children, HIV/AIDS patients and transplant patients on immunosuppressive therapy are reported to suffer from debilitating symptoms when infected with, for instance, T. gondii [25,26]. Our results (Fig-1) also showed a higher prevalence of bacteria (3 out of 4 ) than parasites. This could be attributed to factors such as: geographical locations and the unique life cycles of parasites. As our study was conducted in Shanghai, an urban city, the prevalence of parasites would be comparatively lower than suburbs and suburban areas where the presence of intermediate hosts (birds, rodents and rabbits) is more abundant $[3,7]$. Furthermore, despite the fact that cats are definitive hosts of the parasite Toxoplasmosis, studies have shown that infected cats are limited to excreting $T$. gondii oocysts in stools up to 21 days post-infection [25,27]. After the initial infection, they develop lifelong immunity to further excretion of oocysts unless immunocompromised $[25,28]$. Given the brief window period of oocyst excretion, it is uncommon to detect oocysts in stools of infected cats, as reported by this study involving 563 feral cats, where the average rate was $0.9 \%$ over a three year period [28].

As seen in Table-2, samples that are positive for pathogenic E. coli and S. enterica on PCR and gel electrophoresis were $96 \%-99 \%$ accurate to their respective species using BLAST. The Entam primer was designed to amplify PCR products at 400-50obp for E. histolytica (Table-1). However, samples DA1 and DA2 did not produce bands at the intended base pair level - a 6oobp sequence was amplified instead. Results from BLAST revealed that the sequence in sample DA1 belongs to a plant from the Euphorbiaceae family while the sequence in sample DA2 belongs to a parasite species, Gregarina blattarum (Table-2), which belongs to a group of Apicomplexan alveolates closely related to Toxoplasma and Plasmodium. However, G. blattarum is non-zoonotic; it is an endoparasite that only infects invertebrates, with its host specificity being domiciliary cockroaches. From these findings, Euphorbiaceae and G. blattarum most likely originated from the cats' diet of fiber and insects respectively.

Fig-2 and Fig-3 indicated successful DNA ligation for samples DK4, FA6, FA9 and FA10 where DK4 and FA6 carried the ipaB gene (314bp) for Salmonella spp, while FA9 and FA10 carried the ITS gene (375bp) for Toxocara cati. The original plasmid DNA was 270obp. The expected molecular weight of the ligated DNA is around 30oobp, which was seen in the gel electrophoreses result. Despite evidence supporting samples FA9 and FA1o containing $T$. cati, repeated sequence analyses after DNA amplification did not yield any pathogen sequence using BLAST (Table-2). A Neighbor-Joining (NJ) phylogenetic tree (Fig-4) was created to further investigate samples FA9 and FA10, which revealed the two samples sharing a common ancestor with Schistosoma japonicum, a trematode in clade 12 . The nematode, $T$. cati, is located in clade 11 within this phylogenetic tree. This verifies that samples FA9 and FA10 are more related to $S$. japonicum than T. cati.

The NJ phylogenetic tree in Fig-5 indicates that DNA sequences found in samples DK4 and FA6 are most closely related to each other compared to other Salmonella species. They share a most recent common ancestor (MRCA) with the enteric pathogen Salmonella enterica subspecies Enterica (S. Enterica) as evidenced by node 15 . Infections in humans can involve all species of Salmonella. There are around 2610 different serotypes of Salmonella enterica subspecies enterica and the most commonly known serotypes include Typhimurium, Enteritidis, Typhi, Paratyphi (further subdivided into Types $A, B$ and $C$ ) and Cholerae-suis [29]. There are 3 surface antigens in Salmonella serotypes: the flagellar $\mathrm{H}$ antigen, oligosaccharide $\mathrm{O}$ antigen and polysaccharide Vi antigen (found in Typhi and Paratyphi serotypes). These surface antigens form 
the basis for serotyping Salmonella [30].

S. Typhimurium and S. Enteritidis are non-typhoidal whereas S. typhi and S. Paratyphi are typhoidal. Developed countries have a higher prevalence of nontyphoidal salmonellosis whereas typhoid fever is more prevalent in developing countries (with the most cases in Asia) [30.31]. Approximately 1.3 billion cases of nontyphoidal salmonellosis occur annually worldwide and it has been estimated by WHO that there are 17 million cases and over 500,000 deaths per year caused by typhoid fever [30,31]. In Fig-5, S. Typhi and S. Paratyphi serotypes are non-zoonotic, while the rest are zoonotic, with $S$. Enteriditis and $S$. Typhirium being the most prevalent serotypes infecting humans worldwide [24]. The latter serotype has been identified as an emerging pathogen since 1990, being responsible for numerous outbreaks associated with contaminated food sources as reported in these studies [32-34].

Interestingly, despite identifying $S$. enterica in two of our stool samples (Table-2) from one feral adult cat, FA6, and one domestic kitten, DK4 (Fig-1), both stool samples were non-diarrheic at time of collection. Furthermore, none of the cats and kittens in our study displayed signs of septicemia or gastroenteritis such as anorexia and diarrhea, which are characteristic presentations of clinical salmonellosis; [10] this observation is also seen in studies where a significant majority of cats and dogs infected with Salmonella were asymptomatic carriers that continued to excrete Salmonella in their stools up to 4 weeks [35-37]. The pathogen resides within the host's macrophages in the liver, spleen and intestinal lymph nodes, which become recrudesced and excreted in stools during periods of illnesses or stress in the presence of elevated catecholamines and glucocorticoids [38,39]. Increased frequency of Salmonella excretion under these circumstances can be explained by the pathogen's response to stress hormones, resulting in proliferation and virulence gene expression, scsA gene [39]. This ability of proliferation and excretion is seen as an evolutionary adaptation for the pathogen to propagate by infecting novel hosts upon sensing the current host has seemingly become less healthy. Outside the host, Salmonella is capable of surviving for extended periods of time - this strongly suggests a role in indirect transmission to humans and other animals [36,37].

The ingestion of raw meat via hunting for prey and feeding on commercial raw diets was also hypothesized early in our study as a potential risk factor for cats to acquire enteric zoonoses. This dietary factor predisposes feral cats to have a higher prevalence of enteric pathogens, which is observed in Fig-1. This is especially true for Salmonella, where the highest prevalence (51\%) was reported in shelter and feral cats and dogs [24]. In a 2017 case report, two domestic cats of the same household developed symptoms of gastroenteritis. A stool analysis revealed Salmonella spp. via PCR. Both cats were fed with commercial raw diets, where $S$. Typhimurium was cultured and isolated using real-time PCR. Both cats were also fed with dry pet feed, where no pathogens were isolated in the investigation [40]. This report emphasizes the insidious risk of transmission to humans, which is particularly the case in asymptomatic cats acting as vectors by excreting Salmonella in their stools [35-37].

Furthermore, the recent growing trend of introducing raw meat into the diets of pet cats (either via commercial raw diets or home recipes) may indirectly pose a hazard to human health as the handling of Salmonella-contaminated food source is an established risk for human salmonellosis [8,41]. A comprehensive review explored the prevalence of bacterial pathogens in raw commercial pet foods in North America reported that $7.1 \%$ to $21 \%$ of the samples contained Salmonella [8]. Other countries such as Egypt and the United Kingdom also reported similar values [9,42]. In 2018, two children of the same household were reported with clinical salmonellosis. Investigation revealed identical strains of Salmonella in both children and a commercial raw dog feed that was newly introduced to their pet's diet [43]. Although no further investigation was done to determine if the infection was a result of direct contact with the commercial raw feed or via contact with the pet's stool, the transmission of Salmonella between raw pet feed and humans remained a strongly suggested finding. 
According to case-control and cohort studies, immunocompromised groups of people are most prone to contracting zoonotic pathogens and develop debilitating symptoms $[44,45]$. Hence, they are advised against rearing exotic pets such as reptiles, which are natural reservoirs for salmonellosis $[46,47]$. As this population is at an increased risk of zoonotic diseases, the practice of feeding raw meats to their pets is strongly discouraged. Additionally, they should follow proper pet husbandry techniques that not only minimize stress on their pets, but also reduce high risk activities that may predispose potential zoonotic infections; this includes keeping cats indoors, attending regular vet visits, proper storage of pet feed out of reach from children, placing litter boxes away from the kitchen, etc. Strict hand hygiene practices as well as the routine disinfection of pet and pet feed contact surfaces are also recommended $[47,48]$.

\section{Conclusion}

From the present study, age and dietary factors of cats influence the prevalence of enteric zoonotic pathogens in their stools, where kittens are more susceptible to zoonotic infections and a diet of raw meat is significantly related to a higher prevalence of enteric zoonoses. PCR, when used with diagnostic primers under optimal conditions, followed by sequence analysis, yield adequate results in the detection of zoonotic pathogens to investigate the prevalence of enteric zoonoses in animal stools, and their impact on public health and safety. With the recent trend of commercial raw meat diet for pets, Salmonella has become an increasing concern to public health. Furthermore, as previously discussed, pets remain an insidious source of infection to the immunocompromised population. Aside from taking proper precautions when handling pets, healthcare workers should consider inquiring the pet ownership status of immunocompromised patients during history taking as a routine assessment.

\section{Limitations and Improvements}

I would like to address the limitations encountered in this study and potential improvements to increase the reliability of our findings as well as its future prospects.
Firstly, to increase the sample size from thirty to at least a hundred and classify them by location (e.g., urban, suburban and rural) to explore the significance in geography and zoonoses distribution. Secondly, implement qPCR with species specific primers to obtain reliable results for quantification of pathogen load and ascertain the clinical manifestation of disease [49]. Thirdly, serotyping all Salmonella positive samples to compare with literatures to discern if the serotypes in our study are previously involved in human salmonellosis outbreaks. Fourthly, implement the serotyping results to investigate for antimicrobial resistance and compare their resistance genes, especially in Salmonella positive samples due to a growing concern regarding multi-resistant Salmonella strains causing infected pets to profusely excrete resistant Salmonella in their stools [50]. Finally, from a public health perspective, recognize the need to establish diet strategies to feed feral cats present on university campuses in Shanghai as a means of minimizing zoonotic transmission to the target population of students, who have been observed throughout this study, to routinely engage close contacts with feral cats.

\section{Acknowledgements}

We are very grateful to all participating cat owners and shelter volunteers for the contribution of their cats' stool samples, without whom this study would not have been possible. We would also like to express our sincerest gratitude to Prof. Xunjia Cheng and Dr. Meng Feng for their invaluable guidance and feedback throughout this entire study. Finally, we would like to acknowledge and thank our seniors in the Department of Medical Microbiology and Parasitology for their kind advice and support.

\section{Funding Statement}

This work was supported by the 2017 Fudan University Qing Feng Scholars grant (QF1710) and 2017 FDUROP (Fudan's Undergraduate Research Opportunities Program) Xi Yuan Scholars (grant number 17810). This work was also supported by the National Key Research and Development Program of China (2018YFA0507304). 


\section{Conflict of Interest}

All authors have read and approved the final version of the manuscript. The authors have no conflicts of interest to declare.

\section{Footnote}

Alice Halim and Abhijeet Kumar Bhekarhee both contributed equally to this research.

\section{References}

[1] Zoonoses. Who.int. 2020 [cited 23 November 2020]. Available from:

http://www.who.int/topics/zoonoses/en/

[2] Deplazes P, van Knapen F, Schweiger A, Overgaauw PA. Role of pet dogs and cats in the transmission of helminthic zoonoses in Europe, with a focus on echinococcosis and toxocarosis. Vet Parasitol. 2011 Nov 24;182(1):41-53. [PMID: 21813243]

[3] Chen J, Xu MJ, Zhou DH, Song HQ, Wang CR, Zhu $\mathrm{XQ}$. Canine and feline parasitic zoonoses in China. Parasit Vectors. 2012 Jul 28;5:152. [PMID: 22839365]

[4] Sing A. Cat-related zoonoses: Killing you softly with feces and fleas. In: Zoonoses - Infections Affecting Humans and Animals. Dordrecht: Springer Netherlands; 2015. p. 587-28.

[5] (Möbius, 2013) Möbius, N., Identifikation von Zoonoseerregern bei Haustieren und Bewertung des humanen Infektionsrisikos [Identification of zoonotic pathogens in domestic animals and assessment of the human risk of infection], 2013.

[6] Scorza AV, Duncan C, Miles L, Lappin MR. Prevalence of selected zoonotic and vector-borne agents in dogs and cats in Costa Rica. Vet Parasitol. 2011 Dec 29;183(1-2):178-83. [PMID: 21846585]

[7] Yang Y, Liang H. Prevalence and Risk Factors of Intestinal Parasites in Cats from China. Biomed Res Int. 2015;2015:967238. [PMID: 26078975]

[8] Finley R, Reid-Smith R, Weese JS. Human health implications of Salmonella-contaminated natural pet treats and raw pet food. Clin Infect Dis. 2006 Mar 1;42(5):686-91. [PMID: 16447116]

[9] Azza HE, Sahar MA, Hala SM, Abo-Taleb SM. Evaluation of bacterial hazards in various pet foods. Global Journal of Agriculture and Food Safety Sciences. 2014;1(2):432-39.

[10] Stiver SL, Frazier KS, Mauel MJ, Styer EL. Septicemic salmonellosis in two cats fed a raw-meat diet. J Am Anim Hosp Assoc. 2003 Nov-Dec;39(6):53842. [PMID: 14736718]

[11] Toxocara cati. American Association of Veterinary Parasitologists. 2014 [cited 2020 Nov 23]. Available from:

https://web.archive.org/web/20170509102944/http:// www.aavp.org/wiki/nematodes/ascaridida/toxocaracati/

[12] Scorza AV, Lappin MR. Metronidazole for the treatment of feline giardiasis. J Feline Med Surg. 2004 Jun;6(3):157-6o. [PMID: 15135352]

[13] Stacy-Phipps S, Mecca JJ, Weiss JB. Multiplex PCR assay and simple preparation method for stool specimens detect enterotoxigenic Escherichia coli DNA during course of infection. J Clin Microbiol. 1995 May;33(5):1054-59. [PMID: 7615704]

[14] Li Y, Cao B, Liu B, Liu D, Gao Q, Peng X, Wu J, Bastin DA, Feng L, Wang L. Molecular detection of all 34 distinct O-antigen forms of Shigella. J Med Microbiol. 2009 Jan;58(Pt 1):69-81. [PMID: 19074655]

[15] Kong RY, Lee SK, Law TW, Law SH, Wu RS. Rapid detection of six types of bacterial pathogens in marine waters by multiplex PCR. Water Res. 2002 Jun;36(11):2802-12. [PMID: 12146868]

[16] Sjöling Å, Sadeghipoorjahromi L, Novak D, Tobias J. Detection of major diarrheagenic bacterial pathogens by multiplex PCR panels. Microbiol Res. 2015 Mar;172:34-40. [PMID: 25542594]

[17] Griffais R, André PM, Thibon M. K-tuple frequency in the human genome and polymerase chain reaction. Nucleic Acids Res. 1991 Jul 25;19(14):3887-91. [PMID: 1861980]

[18] Jacobs DE, Zhu X, Gasser RB, Chilton NB. PCRbased methods for identification of potentially zoonotic ascaridoid parasites of the dog, fox and cat. Acta Trop. 1997 Nov;68(2):191-200. [PMID: 9386794]

[19] Som I, Azam A, Bhattacharya A, Bhattacharya S. Inter- and intra-strain variation in the $5.8 \mathrm{~S}$ ribosomal RNA and internal transcribed spacer sequences of Entamoeba histolytica and comparison with Entamoeba dispar, Entamoeba moshkovskii and Entamoeba invadens1New sequence data reported here are deposited in GenBank with the following accession numbers: X89635, Y12249, Y12250 and Y12251.1. Int J Parasitol. 2000;30(6):723-28.

[20] Rivera WL, Tachibana H, Kanbara H. Application of the polymerase chain reaction 
(PCR) in the epidemiology of Entamoeba histolytica and Entamoeba dispar infections. Tokai J Exp Clin Med. 1998 Dec;23(6):413-15. [PMID: 10622639]

[21] Khoshnood S, Rafiei A, Saki J, Alizadeh K. Prevalence and Genotype Characterization of Blastocystis hominis Among the Baghmalek People in Southwestern Iran in 2013 - 2014. Jundishapur J Microbiol. 2015 Oct 18;8(10):e23930. [PMID: 26587213]

[22] Laberge I, Ibrahim A, Barta JR, Griffiths MW. Detection of Cryptosporidium parvum in raw milk by PCR and oligonucleotide probe hybridization. Appl Environ Microbiol. 1996 Sep;62(9):3259-64. [PMID: 8795214]

[23] Appelbee AJ, Frederick LM, Heitman TL, Olson ME. Prevalence and genotyping of Giardia duodenalis from beef calves in Alberta, Canada. Vet Parasitol. 2003 Mar 25;112(4):289-94. [PMID: 12623208]

[24] Salmonellosis. The Center for Food Security \& Public Health. 2013 [cited 2020 Nov 23]. Available from:

http://www.cfsph.iastate.edu/DiseaseInfo/factsheets.p hp

[25] Spickler AR. Toxoplasmosis. The Center for Food Security \& Public Health. 2017 [cited 2020 Nov 23]. Available from:

http://www.cfsph.iastate.edu/DiseaseInfo/factsheets.p hp

[26] Wang ZD, Liu HH, Ma ZX, Ma HY, Li ZY, Yang ZB, Zhu XQ, Xu B, Wei F, Liu Q. Toxoplasma gondii Infection in Immunocompromised Patients: A Systematic Review and Meta-Analysis. Front Microbiol. 2017 Mar 9;8:389. [PMID: 28337191]

[27] Lappin MR. Update on the diagnosis and management of Toxoplasma gondii infection in cats. Top Companion Anim Med. 2010 Aug;25(3):136-41. [PMID: 20937495]

[28] Ahn KS, Ahn AJ, Park SI, Sohn WM, Shim JH, Shin SS. Excretion of Toxoplasma gondii oocysts from Feral Cats in Korea. Korean J Parasitol. 2019 Dec;57(6):66570. [PMID: 31914520]

[29] Su LH, Chiu CH. Salmonella: clinical importance and evolution of nomenclature. Chang Gung Med J. 2007 May-Jun;30(3):210-9. [PMID: 17760271]

[30] Bernard K, Wormser GP. Biodefense principles and pathogens edited by M. s. bronze and R. a. greenfield Norfolk, United Kingdom: Horizon bioscience, 2005. Clin Infect Dis. 2006;42(5):735-35. [31] Chimalizeni Y, Kawaza K, Molyneux E. The epidemiology and management of non typhoidal salmonella infections. Adv Exp Med Biol. 2010;659:3346. [PMID: 20204753]

[32] Centers for Disease Control and Prevention (CDC). Multistate outbreak of Salmonella infections associated with frozen pot pies--United States, 2007. MMWR Morb Mortal Wkly Rep. 2008;57(47):1277-8o. [33] Hauser E, Tietze E, Helmuth R, Junker E, Blank K, Prager R, Rabsch W, Appel B, Fruth A, Malorny B. Pork contaminated with Salmonella enterica serovar 4,[5],12:i:-, an emerging health risk for humans. Appl Environ Microbiol. 2010 Jul;76(14):4601-10. [PMID: 20472721]

[34] Mody RK, Meyer S, Trees E, White PL, Nguyen T, Sowadsky R, Henao OL, Lafon PC, Austin J, Azzam I, Griffin PM, Tauxe RV, Smith K, Williams IT. Outbreak of Salmonella enterica serotype I 4,5,12:i:- infections: the challenges of hypothesis generation and microwave cooking. Epidemiol Infect. 2014 May;142(5):1050-6o. [PMID: 23916064]

[35] Koenig A, Cooper TL, Greene CE, Sharma A, Sakamoto K. Clinical Salmonellosis in a Closed Colony of Blood Donor Cats. Comp Med. 2017 Dec 1;67(6):52428. [PMID: 29212585]

[36] Hoelzer K, Moreno Switt AI, Wiedmann M. Animal contact as a source of human non-typhoidal salmonellosis. Vet Res. 2011 Feb 14;42(1):34. [PMID: 21324103]

[37] Reimschuessel R, Grabenstein M, Guag J, Nemser SM, Song K, Qiu J, Clothier KA, Byrne BA, Marks SL, Cadmus K, Pabilonia K, Sanchez S, Rajeev S, Ensley S, Frana TS, Jergens AE, Chappell KH, Thakur S, Byrum B, Cui J, Zhang Y, Erdman MM, Rankin SC, Daly R, Das S, Ruesch L, Lawhon SD, Zhang S, Baszler T, DiazCampos D, Hartmann F, Okwumabua O. Multilaboratory Survey To Evaluate Salmonella Prevalence in Diarrheic and Nondiarrheic Dogs and Cats in the United States between 2012 and 2014. J Clin Microbiol. 2017 May;55(5):1350-68. [PMID: 28202802]

[38] Greene CE. Enteric bacterial infections,. In: Infectious diseases of the dog and cat. $4^{\text {th }}$ ed. W.B. Saunders $\backslash$ Elsevier Science; 2013. p. 383-88.

[39] Verbrugghe E, Dhaenens M, Leyman B, Boyen F, Shearer N, Van Parys A, Haesendonck R, Bert W, 


\section{Original Article}

Favoreel H, Deforce D, Thompson A, Haesebrouck F, Pasmans F. Host Stress Drives Salmonella Recrudescence. Sci Rep. 2016 Feb 9;6:20849. [PMID: 26857846]

[40] Giacometti F, Magarotto J, Serraino A, Piva S. Highly suspected cases of salmonellosis in two cats fed with a commercial raw meat-based diet: health risks to animals and zoonotic implications. BMC Vet Res. 2017 Jul 24;13(1):224. [PMID: 28738871]

[41] Cobb MA, Stavisky J. Salmonella infections in dogs and cats. In: Salmonella in domestic animals. Wallingford: CABI; 2013. p. 318-36.

[42] Animal and Plant Health Agency. Salmonella in livestock production in Great Britain. Gov.uk. GOV.UK; 2019 [cited 2020 Nov 23]. Available from: https://www.gov.uk/government/publications/salmon ella-in-livestock-production-in-great-britain-2015

[43] Brady C. The first case of Salmonella transmission from raw dog food- DogsFirstIreland. Dogsfirst.ie. 2018 [cited 2020 Nov 23]. Available from: https://dogsfirst.ie/first-case-of-salmonella-from-rawdog-food/

[44] Hung CC, Hung MN, Hsueh PR, Chang SY, Chen MY, Hsieh SM, Sheng WH, Sun HY, Huang YT, Lo YC, Hsiao CF, Chang SC. Risk of recurrent nontyphoid Salmonella bacteremia in HIV-infected patients in the era of highly active antiretroviral therapy and an increasing trend of fluoroquinolone resistance. Clin Infect Dis. 2007 Sep 1;45(5):e6o-67. [PMID: 17682981] [45] Gradel KO, Nørgaard M, Dethlefsen C,
Schønheyder HC, Kristensen B, Ejlertsen T, Nielsen H. Increased risk of zoonotic Salmonella and Campylobacter gastroenteritis in patients with haematological malignancies: a population-based study. Ann Hematol. 2009 Aug;88(8):761-67. [PMID: 19083236]

[46] Steele RW. Should immunocompromised patients have pets? Ochsner J. 2008 Fall;8(3):134-9. [PMID: 21603465]

[47] Stull JW, Brophy J, Weese JS. Reducing the risk of pet-associated zoonotic infections. CMAJ. $2015 \mathrm{Jul}$ 14;187(10):736-43. [PMID: 25897046]

[48] Milanov D S, Aleksić N R, Vidaković S S, Ljubojević D B, Čabarkapa I S. Salmonella spp. in pet feed and risk it poses to humans. Food Feed Res. 2019;46(1):137-45.

[49] Lindsay B, Ochieng JB, Ikumapayi UN, Toure A, Ahmed D, Li S, Panchalingam S, Levine MM, Kotloff K, Rasko DA, Morris CR, Juma J, Fields BS, Dione M, Malle D, Becker SM, Houpt ER, Nataro JP, Sommerfelt H, Pop M, Oundo J, Antonio M, Hossain A, Tamboura B, Stine OC. Quantitative PCR for detection of Shigella improves ascertainment of Shigella burden in children with moderate-to-severe diarrhea in low-income countries. J Clin Microbiol. 2013 Jun;51(6):1740-46. [PMID: 23536399]

[50] Davies RH, Lawes JR, Wales AD. Raw diets for dogs and cats: a review, with particular reference to microbiological hazards. J Small Anim Pract. 2019 Jun;6o(6):329-39. [PMID: 31025713]

Keywords: Zoonotic Pathogen, Zoonosis, Cat Stool, Pet, Salmonella, Public Health, Infectious Disease, PCR, Primer, 